\title{
Pd-membrane Integration in a Propane Dehydrogenation Process for Highly Selective Propylene Production
}

\author{
Antonio Ricca ${ }^{1, *}$, Livia Truda ${ }^{1}$, Gaetano laquaniello ${ }^{2}$, Emma Palo$^{2}$, and Vincenzo Palma ${ }^{1}$ \\ ${ }^{1}$ University of Salerno, Department of Industrial Engineering, via Giovanni Paolo II 132, 84084 Fisciano SA, \\ Italy \\ ${ }^{2}$ KT - Kinetics Technology S.p.A., Viale Castello della Magliana 27, 00148 Rome, Italy
}

\begin{abstract}
The forecasts in the industrial chemistry field evidenced the growing demand of propylene, and the necessity to develop effective processes able to sustain the market. Selective propane dehydrogenation is emerging as the most competitive technology for the production of propylene, on the other hand, the well-known drawback closely linked to the high temperature required to reach a sustainable propane conversion and the coke formation that suppress the catalytic stability still requires appropriate solutions. In this sense, the process intensification through the combination of hydrogen permselective membranes and the reduction of operating temperature could strike the targets of very high propylene selectivity and a quite high conversion value. Since the integration of membrane units in a process required a revision of the operating conditions, the effect of feed composition and temperature was investigated, in order to determine the optimal operating parameters window to operate the system, and assess the overall concept performance. A commercial membrane was characterized, in order to understand the suitability in the propane dehydrogenation process that may cause a severe membrane deactivation due to coke deposition. Finally, specific tests on a simulated process configuration, obtained in an open architecture, confirmed that the smart combination of PDH catalytic reactors and Pdbased membranes was able to allow a reduced operating temperature, so increasing propylene selectivity, and to overcome typical thermodynamic limitations related to a traditional configuration.
\end{abstract}

Keywords: Propane dehydrogenation, Propylene, Pd-based membrane, Process intensification, Membrane inhibition.

\section{INTRODUCTION}

Propylene is one of the most important intermediary product in petrochemical industry since it is a precursor of different chemicals, as polypropylene and acrylonitrile, largely involved in construction, electronic, furniture and automotive industries [1]. Nowadays, its production and in general light olefins production is carried out nearby refinery plants providing stream cracking (SC) and fluid catalytic cracking (FCC) processes [2, 3]. This solution is able to fulfil more than the $90 \%$ of the actual propylene demand. However, the drawback of such processes is the high temperatures involved which lead to low propylene yields [4] as a result of coke formation and side reactions. Asia Pacific regions dominates propylene global market, whose demand increasing was estimated to be $5 \%$ per year until 2018 and is going to increase due to the increasing use of propylene (and acrylonitrile). In order to satisfy the increasing market demand, new and emerging propylene sources are going to keep a straight face, such as propane dehydrogenation (PDH), coal-to-propylene (CTP), and olefin metathesis. Since the consciousness that in the next future traditional

"Address correspondence to this author at the University of Salerno, Department of Industrial Engineering, via Giovanni Paolo II 132, 84084 Fisciano SA, Italy;

Tel: +39 08996 4027; E-mail: aricca@unisa.it processes are not able to keep in balance propylene's supply/demand, it is looking forwards new propylene production technologies. A promising solution is the PDH designed as the most suitable way to overcome conventional processes (SC and FCC) and increasing demand problems.

In (Eq. 1) PDH reaction is reported. It is a highly endothermic reaction, which proceeds with an increase of moles number, so promoted at high temperature and low pressures. Dealing with both high exothermicity and temperatures, this reaction is characterized by coke formation and lighter hydrocarbons production, which are responsible for catalyst deactivation, as well as undesired side reaction occurring.

$$
\mathrm{C}_{3} H_{8} \rightleftarrows \mathrm{C}_{3} \mathrm{H}_{6}+\mathrm{H}_{2} \quad \Delta{H^{o}}^{o}{ }_{298 \mathrm{~K}}=+124 \mathrm{~kJ} / \mathrm{mol}
$$

The available technologies, such as Oleflex, Catofin, STAR, FBD, confined the operating temperature to not more than $650^{\circ} \mathrm{C}$, in order to reduce side reaction relevancy and catalyst deactivation, despite a limited theoretical conversion. On the other hand, side reactions are not limited by thermodynamic equilibrium bringing to low selectivity to propylene with long contact time. For this reason, $\mathrm{DH}$ industrial processes reach limited propane conversion (32-35\%) with a selectivity to propylene below $90 \%$ [5]. 
The critical issue is catalyst deactivation; research is mainly focused on finding more stable formulations starting from chromium- and platinum-based catalysts that are the most commercially used in industrial processes [6]. Surely, Pt-based catalyst arouses more interest not only for its eco-friendly properties but also for its higher catalytic performances: it is able to activate easier $\mathrm{C}-\mathrm{H}$ bonds than $\mathrm{C}-\mathrm{C}$ in $\mathrm{PDH}$ reaction [7]. The addition of $\mathrm{Sn}$ improves Pt-based catalyst activity. In fact, Pt-Sn formulations show higher activity, selectivity and stability; $\mathrm{Sn}$ leads to a decrease of $\mathrm{Pt}$ particle size improving its dispersion [8]. Moreover, the bond strength of chemisorbed hydrocarbons may be modified by adding Sn [9], which may form an alloy with $\mathrm{Pt}[10,11]$. It is likely that Sn plays also an active role in propane dehydrogenation instead to be only a promoter [12, 13]. Nevertheless great efforts in catalyst formulation improvement, coke formation are the main challenge to reduce the repeated catalyst regenerations necessary to avoid catalyst deactivation [14-16]. Low temperatures allow higher selectivity towards desired product despite a reduced conversion of paraffin, thus by tuning operating temperature it is possible to increase propylene selectivity [17]. Different techniques were proposed to optimize catalyst stability and assure longer on-stream time, by means the time between two regeneration cycles. The addition of steam could reduce coke deposition and act on one hand as heat carrier towards the catalytic system, on the other as a diluent of the system, thus promoting under a thermodynamic point of view propane conversion [18]. Hydrogen addition thermodynamically disadvantages propane conversion but it was demonstrated that it assures a very low catalyst deactivation by avoiding both carbon deposition and $\mathrm{Pt}$ sintering [19].

Catalyst deactivation is strictly influenced by reaction temperature: low temperature allows lower deactivation rate [20], following an Arrhenius-like law [21], but at the same time, it forbids propane conversion due to thermodynamic constrains. A possible solution to increase propane conversion could be the addition of oxygen to the reaction volume. This implies to selectively oxidize hydrogen thus enabling further propane conversion but also unavoidable propylene losses [22]. Employing a low temperature dehydrogenation stage with a $\mathrm{H}_{2}$-selective membrane $[23,24]$, able to subtract a product to the system and thus thermodynamically promoting the production of propylene $[25,26]$ could at the same time reduce catalyst deactivation and increase propylene conversion. The most promising membranes are the $\mathrm{Pd}$-based ones not only for their optimal selectivity/flux ratio but for their operative temperature $\left(250-550^{\circ} \mathrm{C}\right)$ too, which are suitable for the PDH reaction [27]. Technically, in the PDH process $\mathrm{Pd}$-membrane is characterized by a depression of permeability performances moving from an $\mathrm{H}_{2}$ /inert mixture to a typical $\mathrm{H}_{2}$ /propane/propylene system mixture [28], which is more noticeable for low hydrogen/propylene ratios [29]. However, Pd-membrane could suffer for typical coking phenomena that reduces its permeability [30] compromising the overall system productivity [31].

Peters et al. [32] investigated the deactivation phenomena of a membrane which occur in a typical $\mathrm{PDH}$ process. In this studies, authors reduced significantly hydrogen flux (up to $34 \%$ in $18.6 \mathrm{~h}$ f TOS) through the perm-selective layer after having introduced propane in the retentate side. A severe deactivation was observed after propylene introduction reaching a complete membrane occlusion in 5 hours. However, a reduction of the operating temperature seemed to mitigate the deactivation leading significant improvement up to $250{ }^{\circ} \mathrm{C}$. Schäfer et al. [33] highlighted that catalytic membrane in a PDH process are more prone to catalyst deactivation owing coke formation than the traditional configurations. Overcoming this problem is possible with a so called "open architecture", where the reaction unit and the separation one operate individually, thus making feasible the use of two different operating temperatures $[34,35]$.

To take on a $\mathrm{H}_{2}$-selectve membrane solution for a $\mathrm{PDH}$ process requires several operating condition to maximize hydrogen partial pressure, as well as low propane dilution and relatively high operating pressure. In literature, there is a lack of papers concerning the catalytic performances evaluation in these uncommon operating conditions and no papers were found about membrane assisted hydrogenation results with concentrate propane mixture. For these reasons, the aim of this work was to carry out a preliminary experimental investigation on $\mathrm{PDH}$ reaction for propylene production assisted by membrane. Operating condition effect on the catalytic performances was evaluated in terms of activity and selectivity. Moreover, the improvement of the addition of a membrane module on the chemical equilibrium of the PDH unit was evaluated, pointing out the optimal operating condition for their integration. 


\section{MATERIALS AND METHODS}

\subsection{Experimental Setup}

Tests were performed at the ProCEEd facilities of the University of Salerno. The experimental plant is constituted by three units: a first catalytic reactor, a membrane separation unit, and a second catalytic reactor; the two catalytic reactors are identical. In the main concept, the process stream was converted in the first reactor (R-101); the produced hydrogen was (partially) separated by the membrane unit (M-101); the resulting stream was further processed in the second reactor (R-102). Such configuration resulted in a socalled "open architecture", in which the separation unit is placed externally between two catalytic stages [36]. It is worth to underline that the process plant was provided by a wide number of valves to by-pass each reaction unit, in order to operate in a marked flexibility: by this configuration, the system can selectively skip one, two or all the modules.

In Figure 1 is reported the layout of the experimental plant.

Catalytic reactors (R-101 and R-102) consists in two identical tubular reactors in AISI $310 \mathrm{H}$ stainless steel tube; the reactors have an external diameter of 33.6 $\mathrm{mm}$, with a wall thickness of $3.78 \mathrm{~mm}$ (corresponding to a nominal diameter of 1 " $\mathrm{SCH} 40$ ) and an overall length of $400 \mathrm{~mm}$. Reactors sealing is assured by a couple of flanges and a spiral wound gasket. Each flange is provided with a blind tube, to host a thermocouple devoted to the evaluation of the temperature inside the reactors (in correspondence to the inlet and outlet sections of the catalytic bed), and a $1 / 4$ " tube connected to the plant piping for the inlet and outlet of the process stream.

The separation module consists of a commercial Pd-based membrane (provided by a confidential supplier). The module is mainly constituted by an AISI $316 \mathrm{~L}$ stainless steel tube (o.d. 1/2"), provided by a porous sector (of about $25.4 \mathrm{~mm}$ ) on which a thin $\mathrm{Pd}$ based perm-selective layer is deposed. Such configuration results in an overall permeating surface of about $0.01 \mathrm{~m}^{2}$. The membrane tube is located in an AISI 316L stainless steel shell (NPS 1" SCH40): shellside flowed the process stream (retentate), while tube side flowed the permeate hydrogen and the sweep gas (permeate).

The temperature control of the process units (both membrane and reactors modules) was assured by a couple of heating wires (provided by Watlow) surrounding the tubular units. For each heating wire, a K-type thermocouple was devoted to evaluate the temperature of the wall of the unit, in order to control the heating of the units; both thermocouples and heating wires are connected to Ascon Tecnologic TLK43 controllers. The units are finally surrounded by a thick layer of quartz wool, to avoid the heat losses. The

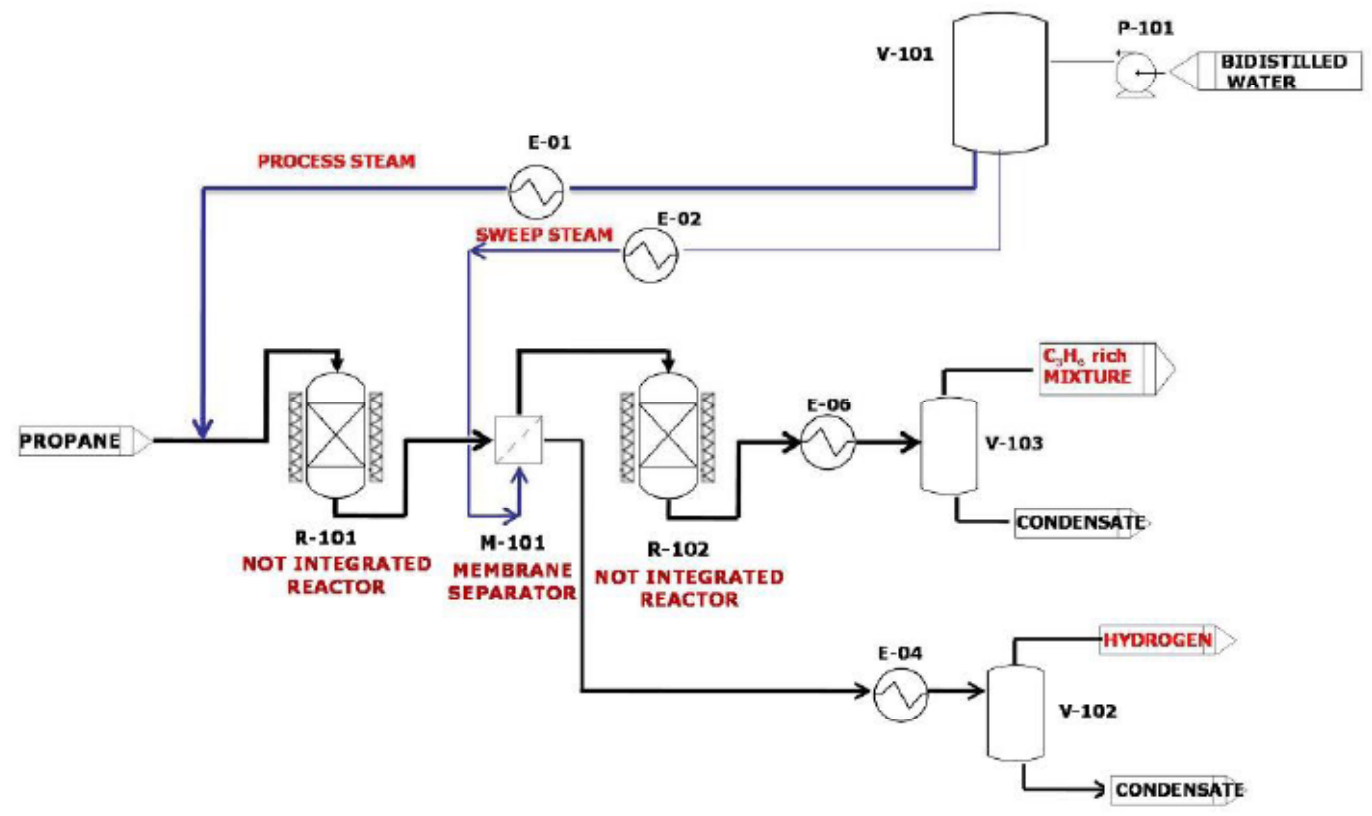

Figure 1: Simplified process scheme of the membrane assisted selective propane dehydrogenation unit in open architecture. 
pressure values of the process were monitored through couples of pressure transducers located upstream and downstream the reactor and the membrane modules. All signals (both pressures and temperatures) were collected by a multipurpose display, and acquired through a labview custom software for the monitoring of the process.

Upstream and downstream the process modules, a couple of 3-way valves were located, allowing the process stream to pass through the module or to bypass it. Another dedicated valve allowed to send to the units a flush stream during the start-up and shutdown procedures, or to send $\mathrm{H}_{2} / \mathrm{N}_{2}$ or $\mathrm{O}_{2} / \mathrm{N}_{2}$ mixtures for the catalyst activation/regeneration activities

The feed section was constituted by a battery of mass flow controllers, provided by Brooks, both thermal based (for the feeding of propane propylene, hydrogen, air and nitrogen) and Coriolis based (for the $\mathrm{H}_{2} \mathrm{O}$ ). In particular, water was delivered to an electrical vaporizer, provided by a heating cartridge, for the steam generation. The overall pressure of the process was controlled by an actuated valve, provided by Barksdale, driven by a TLK43 controller. The whole plant piping and valves were thermostated by a series of heating wires, to assure a process stream temperature of around $180^{\circ} \mathrm{C}$, in order to avoid condensation phenomena in the piping network.

The analysis of the composition of the process stream was carried out by an Agilent Technologies $7820 \mathrm{~A}$ gas chromatograph system, equipped with FID detector, for the analysis of the hydrocarbons, and TCD detectors, for the analysis of $\mathrm{H}_{2}, \mathrm{O}_{2}, \mathrm{~N}_{2}, \mathrm{CO}$ and $\mathrm{CO}_{2}$. A dedicated network of lines was designed to the sampling of the process current along the system, downstream each unit; the sampled stream was dried before to be delivered to the analyzer, in order to avoid condensing phenomena inside the instrument.

\subsection{Experimental Procedure}

The contact time of the process stream in the catalytic volume was defined by fixing the WHSV (in terms of mass flow rate propane fed to the system per mass of catalyst) to $8 \mathrm{~h}^{-1}$ : in this aim, $31.25 \mathrm{~g}$ of catalysts (Pt-based, commercial formulation) was loaded in the reactors, and locked in the middle part of them through two flakes of quartz wool. For the experimental tests on catalyst activity, a propane/steam mixture was assured to the reaction unit: $0.250 \mathrm{~kg} / \mathrm{h}$ of propane was fixed, to assure the set WHSV value; water was added to the process, in order to range steam molar fraction from $6 \%$ to $20 \%$. Such operating conditions resulted in a GHSV between 4,000 and $5,000 \mathrm{~h}^{-1}$ (depending on the steam dilution), higher than typical values in the industrial Catofin and Oleflex processes, for which the GHSV ranged between 600 and $3,600 \mathrm{~h}^{-1}$. The operating pressure was fixed to 5 barg, while the temperature ranged stepwise (through $25^{\circ} \mathrm{C}$ jumps) between $400^{\circ} \mathrm{C}$ and $600^{\circ} \mathrm{C}$.

In order to evaluate the performances of the catalytic system in the selected operating conditions, propane conversion, and selectivities to propylene, coke and light hydrocarbon were defined, as reported in Eq. 2, Eq. 3, Eq. 4 and Eq. 5, where $F_{A}$ indicates the molar rate of the generic compound $A$, while $\mathrm{C}_{n} \mathrm{H}_{m}$ represents the hydrocarbons involved in the process. The coke formation was evaluated by considering the C-balance of the system.

$X_{C_{3} H_{8}}=\frac{F_{C_{3} H_{8}}^{\text {in }}-F_{C_{3} H_{8}}^{\text {out }}}{F_{C_{3} H_{8}}^{\text {in }}}$

$S_{C_{3} H_{6}}=\frac{F_{C_{3} H_{6}}^{\text {out }}}{F_{C_{3} H_{8}}^{\text {in }}-F_{C_{3} H_{8}}^{\text {out }}}$

$S_{C 1-C_{2}}=\frac{F_{C_{4}}^{\text {out }}+F_{C_{2} H_{4}}^{\text {out }}+F_{C_{2} H_{6}}^{\text {out }}}{F_{C_{3} H_{8}}^{\text {in }}-F_{C_{3} H_{8}}^{\text {out }}}$

$S_{\text {coke }}=\frac{F_{\text {coke }}}{F_{C_{3} H_{8}}^{\text {in }}-F_{C_{3} H_{8}}^{\text {out }}}=\frac{3 \cdot F_{C_{3} H_{8}}^{\text {in }}-\sum_{i}\left(n \cdot F_{C_{n} H_{m}}^{\text {out }}\right)}{3 \cdot\left(F_{C_{3} H_{8}}^{\text {in }}-F_{C_{3} H_{8}}^{\text {out }}\right)}$

To better address the experimental results, the propane conversion values observed in the tests were compared to the thermodynamic predictions referred to an ideal propane dehydrogenation stage, in which the only PDH reaction takes place (Eq. 1), and all the other side reactions are inhibited.

Preliminary membrane characterization was carried out by evaluating permeated hydrogen flux at several operating conditions. In a first phase, hydrogen permeation was evaluated by pressurizing retentate side with pure hydrogen, and by measuring the $\mathrm{H}_{2}$ flux in absence of the sweep gas. Such approach assured constant hydrogen partial pressure along the separation module, both at permeate- and retentate- 
sides. Tests were carried out at several operating temperatures, in order to evaluate the effect of temperature on permeation properties. The permeated hydrogen measurement was carried out through a mass flow reader provided by Brooks.

Stability tests for the membrane were performed by keeping constant the temperature of the module, and by feeding a fixed sweep gas in the permeate side (1.5 NL/min of nitrogen). A hydrogen rich stream was fed to the system, in which hydrogen was diluted with a stream composed by propane, propylene and/or steam, to evaluate the effect of other components on the permeation ability of the module. The permeate stream (composed by the sweep gas and the permeate hydrogen) was evaluated by a mass flow reader: by subtracting the sweep flow rate, is possible to evaluate the hydrogen flow rate permeated through the membrane.

The same membrane configuration was adopted for membrane assisted catalytic processes tests.

\section{RESULTS AND DISCUSSION}

\subsection{Catalyst Performance}

The effect of the operating temperature was investigated. Catalytic tests were carried out at 5 barg, to confine the operative range close to the condition of a membrane-assisted process, in which the retentate pressure should be held high enough to promote the hydrogen permeation. In addition, tests were performed at different $\mathrm{C}_{3} \mathrm{H}_{8}: \mathrm{H}_{2} \mathrm{O}$ ratio, to recognize the role of the presence of steam in the reaction system. Test results, summarized in Figure 2, evidenced that, for $\mathrm{C}_{3} \mathrm{H}_{8}: \mathrm{H}_{2} \mathrm{O}$ $=80: 20$, experimental conversion was close enough to the thermodynamic conversion. It is however worth to note that, by increasing reaction temperature,

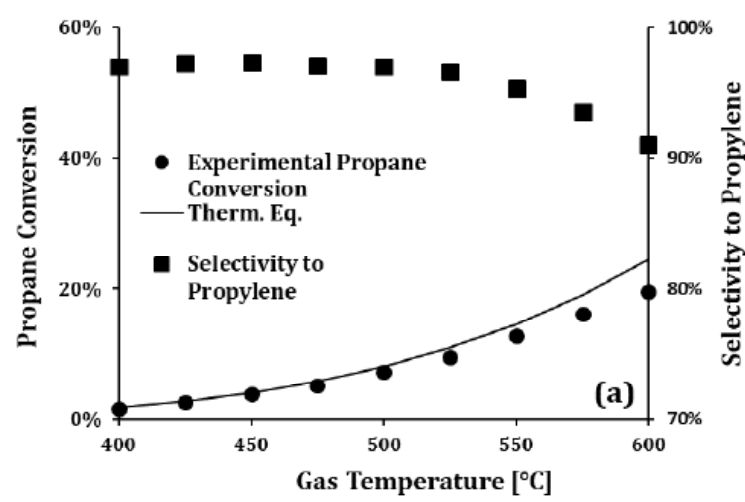

experimental conversion showed a growing discordance to the thermodynamic prediction. As a first approach, such behaviour could suggest a partial deactivation of the catalyst during the test procedure (the temperature was increased stepwise along the test, each temperature was held for at least 40 minutes). On the other hand, it is also not negligible the occurrence of reactions in homogeneous phase downstream the catalytic bed, in the cooling phase of the process stream, that can induce to a propylene rehydrogenation. The analysis of the process selectivity evidenced that at low temperature (below $525^{\circ} \mathrm{C}$ ) a very high selectivity to propylene (>97\%) was recorded, whereas a total absence of gaseous side products could be observed, while the coke formation was relatively low. At higher operating temperature, a slight increase of coke selectivity was observed, while the production of $\mathrm{C} 1-\mathrm{C} 2$ side products appeared more relevant, consequently, the selectivity to propylene was depressed up to around $90 \%$.

The same test was repeated for the $\mathrm{C}_{3} \mathrm{H}_{8}: \mathrm{H}_{2} \mathrm{O}=$ $88: 12$, results were summarized in Figure 3 . The propane conversion trend is quite similar to the previous case, where a higher dilution with steam was adopted: it was however evident a better approach to the thermodynamic equilibrium. On the other hand, the selectivity to propylene appeared clearly lower, being below $95 \%$ in all the investigated range. Therefore, it is reasonable to think that the better approach to thermodynamic equilibrium was due to the contribution of side reactions [37]. The selectivity to coke was similar to the previous case for the whole operating range, on the other hand a marked increase in the selectivity to gaseous side-products could be observed, that once again increased at higher temperatures, up to reach values close to $7 \%$. It was also worth to underline that in both feeding conditions, no $\mathrm{CO}$ and $\mathrm{CO}_{2}$ production was detected, so suggesting the total

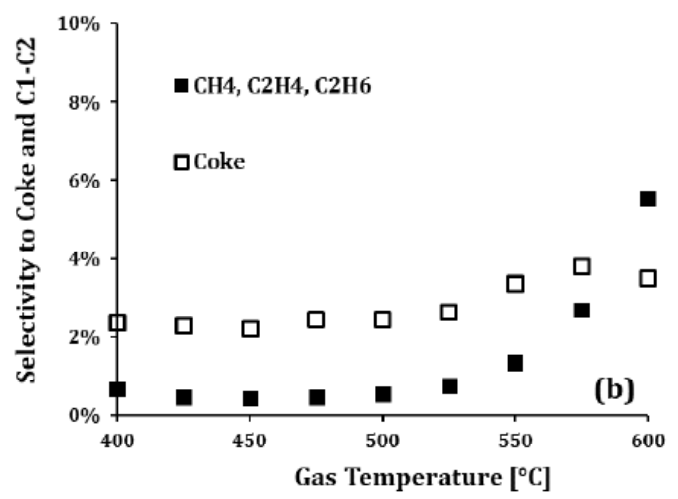

Figure 2: Propane conversion and selectivity trends (WHSV $=8 \mathrm{~h}^{-1}, 5$ barg; $\mathrm{C}_{3} \mathrm{H}_{8}: \mathrm{H}_{2} \mathrm{O}=80: 20$ ). 

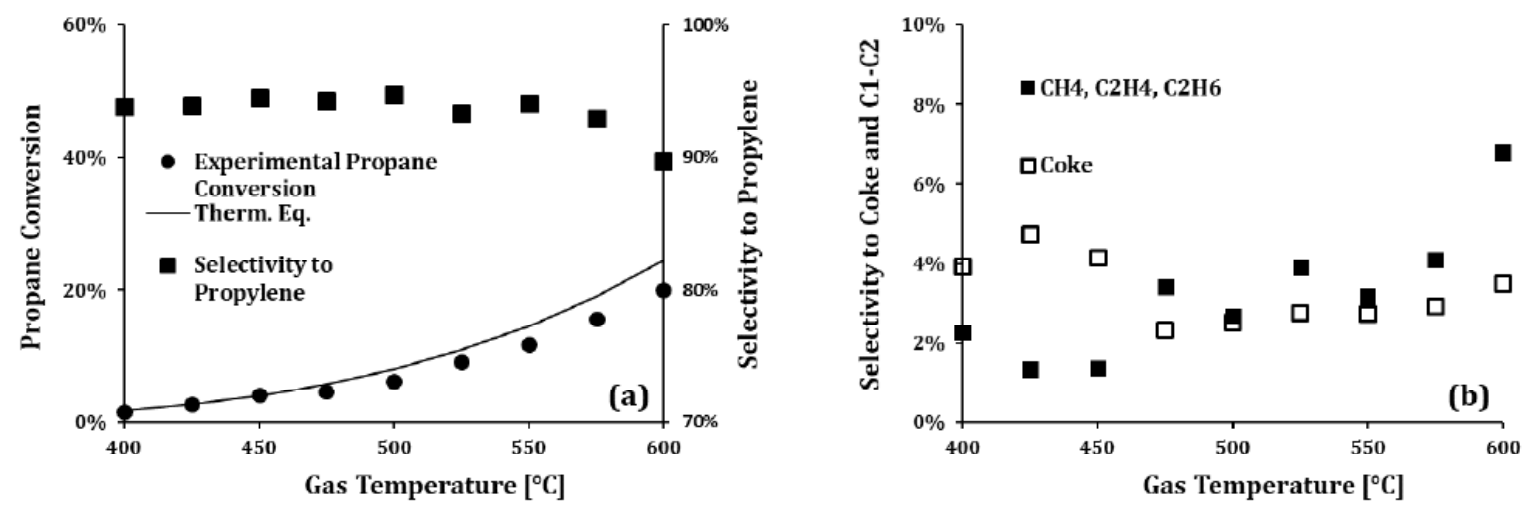

Figure 3: Propane conversion and selectivity trends (WHSV $=8 \mathrm{~h}^{-1} ; 5$ barg; $\mathrm{C}_{3} \mathrm{H}_{8}: \mathrm{H}_{2} \mathrm{O}=88: 12$ ).

absence of reforming reactions. Such phenomenon could suggest that one of the main role of steam in the propane dehydrogenation is to suppress the sidereactions leading to the lighter hydrocarbons.

By reducing again the steam content, by feeding a process stream with $\mathrm{C}_{3} \mathrm{H}_{8}: \mathrm{H}_{2} \mathrm{O}=95: 5$ (Figure 4), the propane conversion showed a good overlap with thermodynamic predictions, on the other hand the very low selectivity with respect the propane dehydrogenation reaction was observed. The lack of steam in the process feed caused a dramatic production of coke in the process, as well as of gaseous side-products; such trend was further intensified by increasing operating temperature, since at $575^{\circ} \mathrm{C}$ the coke selectivity overcomes the value of $20 \%$, while the selectivity to gaseous side-products reached the $12 \%$.

\subsection{Membrane Characterization}

The $\mathrm{H}_{2}$ permeation properties of the membrane were investigated, by evaluating the parameters of the generalized permeation law reported in Eq. 6 .

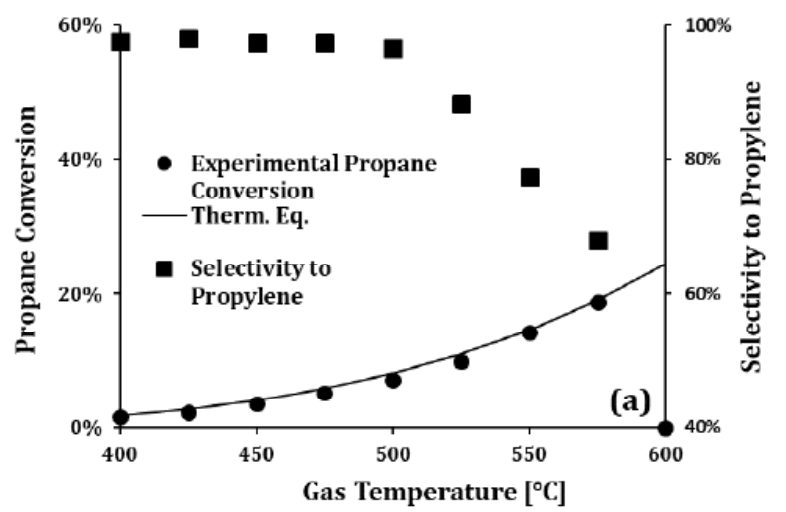

$j_{H_{2}}=\frac{P e}{\delta} \cdot\left[\left(p_{H_{2}, \text { ret }}\right)^{n}-\left(p_{H_{2}, \text { perm }}\right)^{n}\right]$

Experimental tests were performed by varying the temperature between 370 and $450^{\circ} \mathrm{C}$. For each temperature, the reactor was pressurized with hydrogen stepwise from 2 to 6 bar, in order to evaluate the hydrogen flux in every conditions. For all the investigated temperature, it was evaluated the linear fitting of $j_{H 2}$ vs $\left(p_{H 2, \text { ret }}\right)^{n}-\left(p_{H 2, \text { perm }}\right)^{n}$ plots for different $n$ values in the range $0.5-1.0$ : the fitting effectiveness was estimated via the determination factor (R2). The study of the dependence of the determination factor from the $n$ parameter will enable the evaluation of the optimal $\mathrm{n}$ value, being the one that maximize $R 2$. In the Figure 5 the evaluation of $n$ for the investigated temperatures was reported.

The overall optimization identified $n=0.72$ as the best value, for which a global $R 2=0.988$ was obtained .

Dedicated tests were carried out also on the membrane by applying nitrogen at 6 bar, and by evaluating the permeate rate. For all the investigated

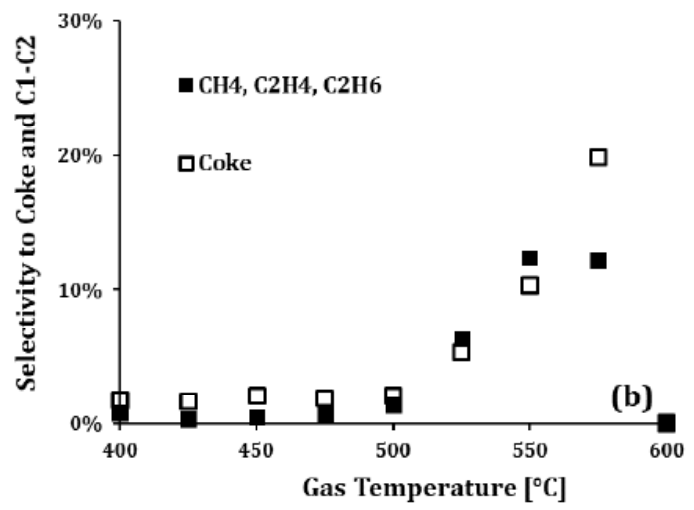

Figure 4: Propane conversion and selectivity trends (WHSV $\left.=8 \mathrm{~h}^{-1} ; 5 \mathrm{barg} ; \mathrm{C}_{3} \mathrm{H}_{8}: \mathrm{H}_{2} \mathrm{O}=94: 6\right)$. 



Figure 5: Hydrogen flux dependence to the corrected hydrogen partial pressure gradient through membrane and experimental points linearization dependence from " $n$ " parameter for the investigated temperature.

temperature, a nitrogen flux of around $8 \mathrm{NmL} / \mathrm{min}$ was recorded, thus resulting in a $\mathrm{H}_{2} / \mathrm{N}_{2}$ selectivity of around 350 at $370^{\circ} \mathrm{C}$ up to 480 at $450^{\circ} \mathrm{C}$. Such behaviour could be justified with a leak probably due to a palladium layer defect.
Once fixed the pressures exponential, it is possible to evaluate the permeability parameter, and its dependence from the temperature. The Richardson law (Eq. 7) directly correlates hydrogen flux $\left(j_{H_{2}}\right)$ and hydrogen partial pressure through the permeance 
$(P e / \delta$, where $P e=$ permeability, and $\delta=$ membrane layer thickness) and the exponential $n$. The permeance depends on operating temperature through an Arrhenius like correlation, for which $P e_{0} / \delta$ and $E_{a}$ parameters should be evaluated.

$j_{H_{2}}=\frac{P e_{0} \cdot e^{\frac{-E_{a}}{R \cdot T}}}{\delta} \cdot\left[\left(p_{H_{2}, \text { ret }}\right)^{n}-\left(p_{H_{2}, \text { perm }}\right)^{n}\right]$

The dependence of the temperature on the permeated flux was summarized in the Figure 6: as reported, the increasing of temperature strongly effected the hydrogen permeance, since by raising temperature from 370 to $450^{\circ} \mathrm{C}$ hydrogen flux showed a gain of around $35 \%$. According to Richardson correlation, membrane permeance increases by increasing temperature: the permeance values for each T were reported in Table 1.

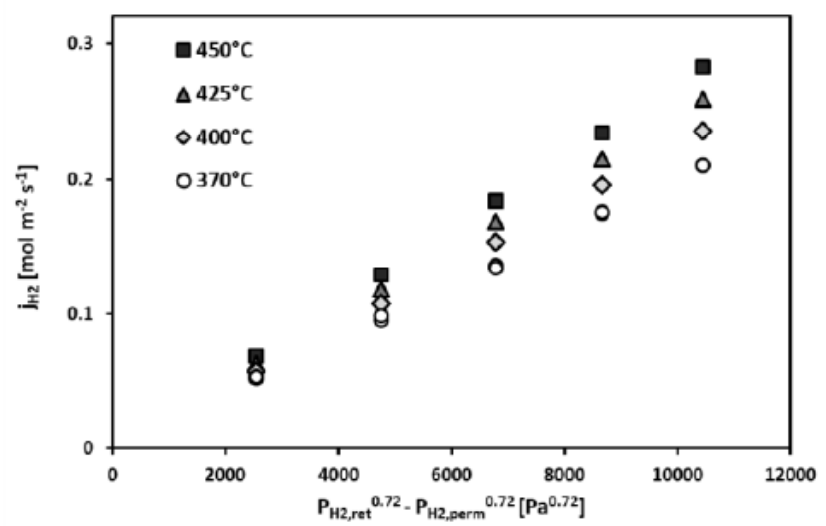

Figure 6: Hydrogen permeated flux dependence on the membrane temperature.

Table 1: Permeance Dependence on Operating Temperature

\begin{tabular}{|c|c|}
\hline Temperature $\left[{ }^{\circ} \mathrm{C}\right]$ & $P e / \delta\left[\mathrm{mol} \mathrm{s}^{-1} \mathbf{~ m}^{-2} \mathbf{P a}^{-0.72}\right]$ \\
\hline \hline 370 & $2.02 \times 10^{-5}$ \\
\hline 400 & $2.26 \times 10^{-5}$ \\
\hline 425 & $2.44 \times 10^{-5}$ \\
\hline 450 & $2.71 \times 10^{-5}$ \\
\hline
\end{tabular}

The membrane parameters for the Richardson law were achieved by the Arrhenius linearization (In $\mathrm{Pe} / \delta$ vs $1 / T)$, reported in the Figure 7 . Such analysis allowed to estimate the permeance parameters $P e_{0} / \delta=2.65 \times$ $10^{-4} \mathrm{~mol} \mathrm{~m}^{-2} \mathrm{~Pa}^{-0.72}$ and $E_{a}=13.76 \mathrm{~kJ} / \mathrm{mol}$.

Dedicated tests were carried out to understand the stability of the membrane to critical environments, to evaluate its suitability for the propane dehydrogenation

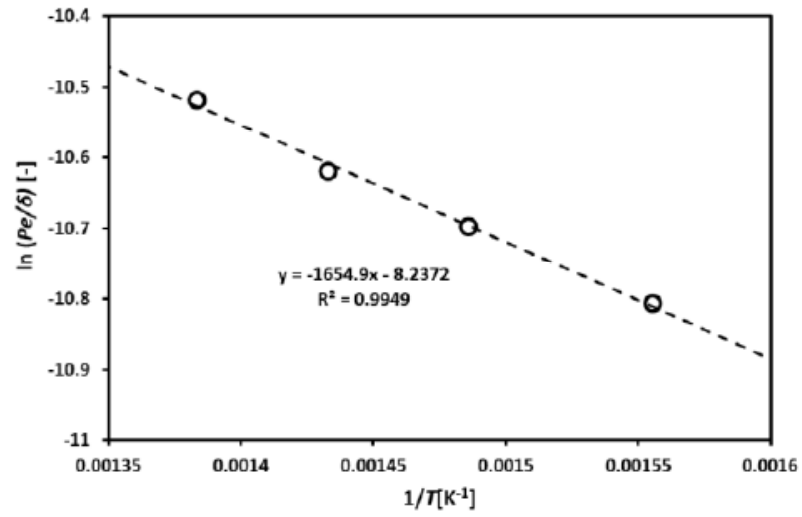

Figure 7: Arrhenius diagram of permeance dependence on membrane temperature.

process: the presence of propane and/or propylene in the retentate stream could suppress both reversibly or irreversibly the permeability of the membrane. Stability tests were carried out by feeding the membrane with a process stream $(2.5 \mathrm{NL} / \mathrm{min})$ held at 5 barg containing $20 \mathrm{vol} \%$ of hydrogen in nitrogen, propane or propane/propylene mixture (70 vol\% propane, $10 \mathrm{vol} \%$ propylene); no sweep gas was fed to the permeate side. The effect of temperature on the membrane stability was also evaluated. In the Figure 8 the efficiency reduction of the membrane separation was summarized: the normalized flux was defined as the ratio between the measured permeated hydrogen flux, and the same flux obtained by feeding the mixture $\mathrm{H}_{2} / \mathrm{N}_{2}$.

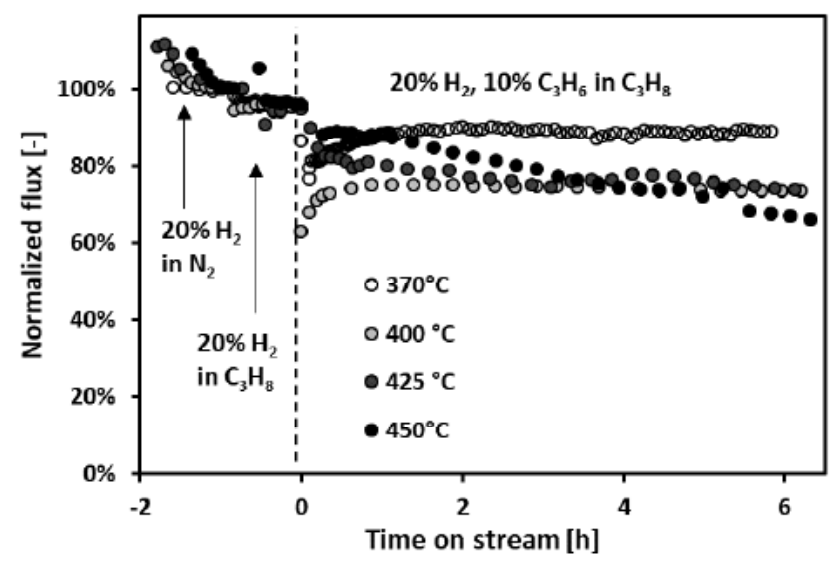

Figure 8: Dependence of permeate flux through the membrane to the presence of propane and propylene (5 bargretentate side, no sweep).

In the first part of the test, the membrane was stabilized through a hydrogen/nitrogen mixture, in order to define the starting value of hydrogen flux. Then the inert was replaced by propane: the introduction of the hydrocarbon caused a relevant drop in the membrane 
permeation for all the operating conditions. The effect of the propane seems to be independent from the operating temperature, since in all the investigated cases the permeation drop was confined in 4-6\%. Such inhibition phenomenon could be addressed to a competitive propane adsorption on the membrane surface, resulting in a further resistance for the hydrogen permeation [38]; it is anyway worth noting that while for the lowest operating temperature the membrane performances appeared quite constant, for the other temperatures a non-negligible deactivation trend could be noticed, more evident for the tests carried out at 425 and $450^{\circ} \mathrm{C}$. Therefore, the flux reduction was due not only to a transient phase in which propane was adsorbed on palladium layer; in fact, a membrane plugging could be observed for the high temperature. In a second step, propylene was added to the process stream: for the lower temperatures, an initial permeate flux reduction could be observed, evaluated around $11 \%$ (at $370^{\circ} \mathrm{C}$ ) and $20 \%\left(\right.$ at $400^{\circ} \mathrm{C}$ ) of the initial value, however permeation values progressively increased up to recover its activity recorded in absence of propylene. The reason of such behaviour was not well understood; it could be devoted to surface reactions between involved species. On the other hand, at $425^{\circ} \mathrm{C}$ and $450^{\circ} \mathrm{C}$ the membrane deactivation appeared enhanced by the addition of the olefin that in particular at $450^{\circ} \mathrm{C}$ caused a flux reduction up to $30 \%$ in less than 6 hours of tests. In a general context, it is evident that, beside the initial permeation drop, the operating temperature severely affected the membrane deactivation rate, since the higher the operating temperature, the higher is the decreasing slope of hydrogen flux. Performed tests evidenced that operating temperature was critical for the stability of the membrane in a hydrocarbons-rich environment, since in similar conditions the membrane performances were very stable by operating at $370^{\circ} \mathrm{C}$ also in the presence of the propylene for the entire on-stream time (about 6 hours). Such achievement was really impressive, also by comparing to other experiences reported in the literature: Montesinos et al. [28] reported that propylene adsorption on palladium layer is higher than propane, causing the formation of carbonaceous matter on the membrane surface [39], moreover the unsaturated propylene has a high tendency to form oligomers and ring structures compared to propane [32]. It is anyway fair to remark that to operate at lower temperature could further improve membrane resistance to deactivation under hydrocarbons rich conditions, as also reported by Peters et al. [32] and Jung et al. [40], despite a non-negligible flux reduction.
Finally, the effect of the presence of the steam was also investigated. Tests were carried out by feeding in the retentate side at the beginning a $2.5 \mathrm{NL} / \mathrm{min}$ of a stream composed by $80 \%$ of propane, $5 \%$ of propylene and $5 \%$ of hydrogen; then the steam was added to the retentate, and propane content was reduced to keep constant the hydrogen and propylene volumetric fractions. The membrane was held at $370^{\circ} \mathrm{C}$, while the retentate pressure was set to 5 barg. In the permeate side, a nitrogen stream (1.5 NL/min) was fed as sweep gas, to reduce the hydrogen partial pressure. The effect of steam on the permeated hydrogen flux is reported in the Figure 9. As evidenced by the experimental results, the steam seems to partially inhibit the hydrogen permeation through the membrane: such achievement well agrees with other studies reported in the literature, evidencing that the excess of steam leads to a sensible reduction in membrane permeability due to a competitive adsorption of $\mathrm{H}_{2} \mathrm{O}$ on $\mathrm{Pd}$ surface [4]. It is anyway worth to consider that the presence of steam in a similar system is mandatory, due to the well-known tendency of involved hydrocarbons to the cracking reactions and to the coke formation. In this sense, the presence of steam in the retentate stream could suppress of coke deposition rate, thus presuming a longer lifetime of the membrane [42].

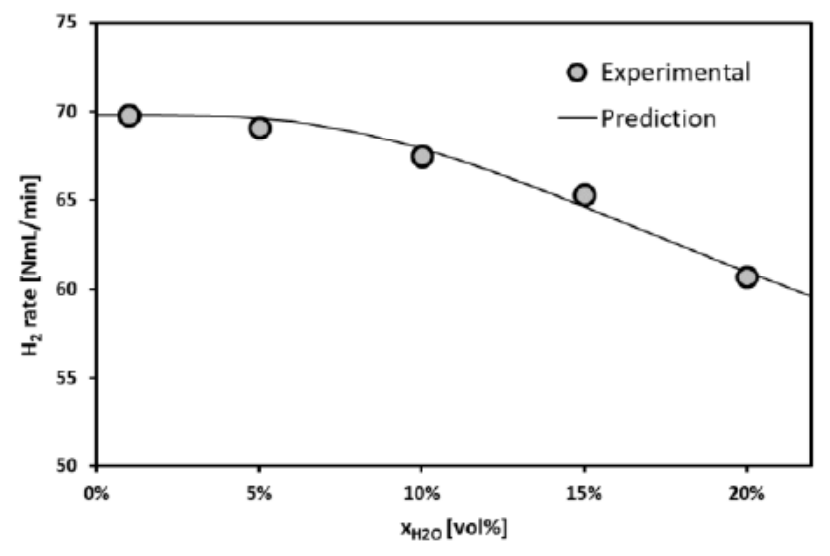

Figure 9: Effect of the presence of steam on the membrane permeance $\left(370^{\circ} \mathrm{C}, 5\right.$ barg, $\left.x_{H 2}=5 \%, Q_{\text {sweep }}=1.5 \mathrm{NL} / \mathrm{min}\right)$.

\subsection{Membrane-Based System Operation}

The real advantages of coupling catalytic reactors with separation units were evaluated in an experimental campaign performed by simulating a system constituted by 3 catalytic unit separated by 2 membranes, resulting so an open architecture membrane assisted process R-101 - M-101 - R-102 M-102 - R-103 (Figure 10). The proposed configuration 


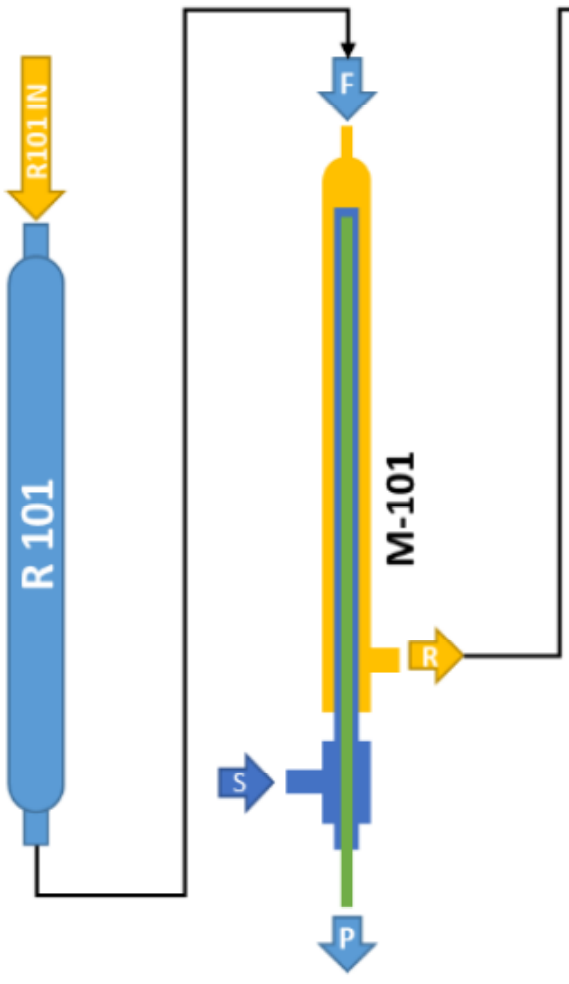

Figure 10: Membrane assisted process scheme configuration.

was arranged by exploiting the available experimental system, composed by two reactors and a membrane unit between them. In a first stage, the system was employed by feeding the reactants in the first reactor $(\mathrm{R}-101)$, the products were delivered to the separation unit $(M-101)$ for the hydrogen recovery, then the membrane retentate was fed to the second reactor (R-102), to carry on the catalytic process. In a second phase, a simulated process stream, with identical composition to the products of the second reactor of the first stage, was delivered to the membrane that so acted as $M-102$, then the retentate was fed to the following reactor that acted as R-103. In such arrangement, each separation unit placed downstream the reaction unit, aimed to (partially) remove hydrogen from the process stream, thus enabling the subsequent catalytic stage to a further conversion of the propane, and as a consequence, to a further production of propylene. All catalytic units were loaded with $32.25 \mathrm{~g}$ of catalyst, while the operating temperature was set to $500^{\circ} \mathrm{C}$. The membrane temperature was set to $370^{\circ} \mathrm{C}$, in order to minimize the deactivation effects, and a sweep stream, composed by $1.5 \mathrm{NL} / \mathrm{min}$ of nitrogen, was fed in the permeate side. Experimental tests were carried out by processing two feed streams, in which the water content was changed: in the first one a
$\mathrm{C}_{3} \mathrm{H}_{8}: \mathrm{H}_{2} \mathrm{O}=80: 20$ was set, while in the second one the steam content was reduced, up to have a $\mathrm{C}_{3} \mathrm{H}_{8}: \mathrm{H}_{2} \mathrm{O}=$ $88: 12$. For both tests, the propane flow rate was fixed to $0.25 \mathrm{~kg} / \mathrm{h}$, in order to keep constant the WHSV value.

The performances of the evaluated system were summarized in Figure 11. Reported results evidenced that in all the catalytic stages the propane conversion to propylene occurred; obviously, the main part of the conversion took place in the first reactor (R-101), while the advancements in reactants conversion observed in the other two reactors was due to the hydrogen partial removal assured by the membrane units. It was worth to note that, beside the similar performances of the R101 in both operating conditions, overall high propane conversion could be recorded for the lowest diluted feed, in opposition to thermodynamic predictions, that forecast a direct dependency of the propane conversion to the feed dilution.

To elucidate the behaviour of the system, the performances of the individual units were investigated: in particular, the propane conversion for each catalytic unit was evaluated, and compared to the thermodynamic equilibrium of the unit; in addition, the 
Table 2: Estimated Volumetric Flow Rates along the Experimental System $m$ by Feeding $\mathrm{C}_{3} \mathrm{H}_{8}: \mathrm{H}_{2} \mathrm{O}=88: 12$ $\left(\right.$ WHSV $\left.=8 \mathrm{~h}^{-1}\right)$

\begin{tabular}{|c|c|c|c|c|c|c|c|c|c|c|c|c|}
\hline & \multirow[t]{2}{*}{ R101 IN } & \multirow[t]{2}{*}{ R-101 OUT } & \multicolumn{4}{|c|}{ M-101 } & \multirow[t]{2}{*}{ R-102 OUT } & \multicolumn{4}{|c|}{ M-101 } & \multirow[t]{2}{*}{ R-103 OUT } \\
\hline & & & $\mathbf{F}$ & $\mathbf{R}$ & $\mathbf{S}$ & $\mathbf{P}$ & & $\mathbf{F}$ & $\mathbf{R}$ & $\mathbf{S}$ & $\mathbf{P}$ & \\
\hline$T\left[{ }^{\circ} \mathrm{C}\right]$ & 500 & 370 & 370 & 370 & 370 & 370 & 500 & 370 & 370 & 370 & 370 & 500 \\
\hline$p$ [barg] & 5.00 & 5.00 & 5.00 & 5.00 & 0.04 & 0.04 & 5.00 & 5.00 & 5.00 & 0.04 & 0.04 & 5.00 \\
\hline$Q[N c c / m i n]$ & 2412.5 & 2565.8 & 2565.8 & 2474.8 & 1500.0 & 1591.0 & 2522.0 & 2522.0 & 2467.0 & 1500.0 & 1555.0 & 2503.9 \\
\hline $\mathrm{H}_{2}$ & & 153.0 & 153.0 & 61.8 & & 88.6 & 110.6 & 110.6 & 60.2 & & 50.4 & 101.0 \\
\hline $\mathrm{CH}_{4}$ & & 1.2 & 1.2 & 1.3 & & 0.0 & 1.3 & 1.3 & 1.0 & & 0.0 & 1.3 \\
\hline $\mathrm{C}_{2} \mathrm{H}_{4}$ & & 0.1 & 0.1 & 0.1 & & 0.0 & 0.2 & 0.2 & 0.1 & & 0.0 & 0.2 \\
\hline $\mathrm{C}_{2} \mathrm{H}_{6}$ & & 2.4 & 2.4 & 2.2 & & 0.0 & 1.4 & 1.4 & 1.0 & & 0.0 & 1.3 \\
\hline $\mathrm{C}_{3} \mathrm{H}_{6}$ & & 150.4 & 150.4 & 151.4 & & 0.2 & 211.3 & 211.3 & 208.3 & & 0.5 & 243.1 \\
\hline $\mathrm{C}_{3} \mathrm{H}_{8}$ & 2123.0 & 1967.8 & 1967.8 & 1967.4 & & 2.2 & 1907.4 & 1907.4 & 1907.4 & & 4.1 & 1869.2 \\
\hline $\mathrm{C}_{4} \mathrm{H}_{8}$ & & 0.3 & 0.3 & 0.4 & & 0.0 & 0.0 & 0.0 & 0.0 & & 0.0 & 0.1 \\
\hline $\mathrm{C}_{4} \mathrm{H}_{10}$ & & 1.1 & 1.1 & 1.3 & & 0.0 & 0.8 & 0.8 & 0.1 & & 0.0 & 0.1 \\
\hline$N_{2}$ & & 0.0 & 0.0 & 0.0 & 1500.0 & 1500.0 & 0.0 & 0.0 & 0.0 & 1500.0 & 1500.0 & 0.0 \\
\hline $\mathrm{CO}$ & & 0.0 & 0.0 & 0.0 & & 0.0 & 0.0 & 0.0 & 0.0 & & 0.0 & 0.0 \\
\hline $\mathrm{CO}_{2}$ & & 0.0 & 0.0 & 0.0 & & 0.0 & 0.0 & 0.0 & 0.0 & & 0.0 & 0.0 \\
\hline $\mathrm{H}_{2} \mathrm{O}$ & 289.5 & 289.5 & 289.5 & 289.0 & & 0.5 & 289.0 & 289.0 & 289.0 & & 0.0 & 289.0 \\
\hline$X_{\mathrm{C} 3 \mathrm{H} 8}$ & & $7.3 \%$ & & & & & $3.0 \%$ & & & & & $2.0 \%$ \\
\hline Mem. Effic. & & & & & & $58.0 \%$ & & & & & $45.6 \%$ & \\
\hline
\end{tabular}

Table 3: Estimated Volumetric Flow Rates along the Experimental System $m$ by Feeding $\mathrm{C}_{3} \mathrm{H}_{8}: \mathrm{H}_{2} \mathrm{O}=80: 20$ (WHSV $=8 \mathrm{~h}^{-1}$ )

\begin{tabular}{|c|c|c|c|c|c|c|c|c|c|c|c|c|}
\hline & \multirow[t]{2}{*}{ R101 IN } & \multirow[t]{2}{*}{ R-101 OUT } & \multicolumn{4}{|c|}{ M-101 } & \multirow[t]{2}{*}{ R-102 OUT } & \multicolumn{4}{|c|}{ M-101 } & \multirow[t]{2}{*}{ R-103 OUT } \\
\hline & & & $\mathbf{F}$ & $\mathbf{R}$ & $S$ & $\mathbf{P}$ & & $\mathbf{F}$ & $\mathbf{R}$ & $\mathbf{S}$ & $\mathbf{P}$ & \\
\hline$T\left[^{\circ} \mathrm{C}\right]$ & 500 & 370 & 370 & 370 & 370 & 500 & 370 & 370 & 370 & 370 & 500 & 500 \\
\hline$p$ [barg] & 5.00 & 5.00 & 5.00 & 0.04 & 0.04 & 5.00 & 5.00 & 5.00 & 0.04 & 0.04 & 5.00 & 5.00 \\
\hline$Q[\mathrm{Ncc} / \mathrm{min}]$ & 2412.5 & 2812.8 & 2812.8 & 2721.8 & 1500.0 & 1591.0 & 2769.5 & 2769.5 & 2714.5 & 1500.0 & 1555.0 & 2737.5 \\
\hline $\mathrm{H}_{2}$ & & 159.0 & 159.0 & 84.9 & & 73.4 & 134.1 & 134.1 & 86.6 & & 44.0 & 111.2 \\
\hline $\mathrm{CH}_{4}$ & & 1.0 & 1.0 & 1.0 & & 0.0 & 1.0 & 1.0 & 0.9 & & 0.0 & 1.0 \\
\hline $\mathrm{C}_{2} \mathrm{H}_{4}$ & & 0.1 & 0.1 & 0.1 & & 0.0 & 0.2 & 0.2 & 0.2 & & 0.0 & 0.2 \\
\hline $\mathrm{C}_{2} \mathrm{H}_{6}$ & & 1.1 & 1.1 & 1.0 & & 0.0 & 1.2 & 1.2 & 1.2 & & 0.0 & 1.3 \\
\hline $\mathrm{C}_{3} \mathrm{H}_{6}$ & & 158.6 & 158.6 & 153.9 & & 0.2 & 202.4 & 202.4 & 202.5 & & 0.4 & 226.5 \\
\hline $\mathrm{C}_{3} \mathrm{H}_{8}$ & 2123.0 & 1963.0 & 1963.0 & 1951.6 & & 2.2 & 1901.4 & 1901.4 & 1893.9 & & 2.9 & 1868.0 \\
\hline $\mathrm{C}_{4} \mathrm{H}_{8}$ & & 0.0 & 0.0 & 0.0 & & 0.0 & 0.0 & 0.0 & 0.0 & & 0.0 & 0.0 \\
\hline $\mathrm{C}_{4} \mathrm{H}_{10}$ & & 0.0 & 0.0 & 0.0 & & 0.0 & 0.1 & 0.1 & 0.1 & & 0.0 & 0.1 \\
\hline$N_{2}$ & & 0.0 & 0.0 & 0.0 & 1500.0 & 1515.2 & 0.0 & 0.0 & 0.0 & 1500.0 & 1507.7 & 0.0 \\
\hline $\mathrm{CO}$ & & 0.0 & 0.0 & 0.0 & & 0.0 & 0.0 & 0.0 & 0.0 & & 0.0 & 0.0 \\
\hline $\mathrm{CO}_{2}$ & & 0.0 & 0.0 & 0.0 & & 0.0 & 0.0 & 0.0 & 0.0 & & 0.0 & 0.0 \\
\hline $\mathrm{H}_{2} \mathrm{O}$ & 530.1 & 530.1 & 530.1 & 529.2 & & 0.9 & 529.2 & 529.2 & 529.2 & & 0.0 & 529.2 \\
\hline$X_{\text {Сзнв }}$ & & $7.5 \%$ & & & & & $2.6 \%$ & & & & & $1.4 \%$ \\
\hline Mem. Effic. & & & & & & $46.1 \%$ & & & & & $32.8 \%$ & \\
\hline
\end{tabular}

efficiency of the separation units, defined as the ratio between the permeated hydrogen with respect to the fed hydrogen, was calculated. 


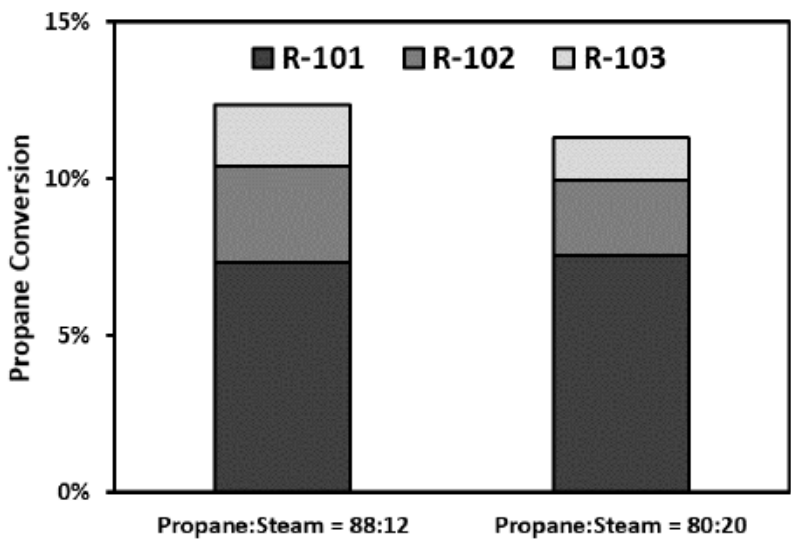

Figure 11: Propane conversion along the membrane assisted system by feeding $\mathrm{C}_{3} \mathrm{H}_{8}: \mathrm{H}_{2} \mathrm{O}=88: 12$ (a) and $\mathrm{C}_{3} \mathrm{H}_{8}: \mathrm{H}_{2} \mathrm{O}=80: 20$ (b) $\left(\mathrm{W}_{\mathrm{C} 3 \mathrm{H} 8}=0.25 \mathrm{~kg} / \mathrm{h} ; \mathrm{WHSV}=8 \mathrm{~h}^{-1}, \mathrm{~T}_{\text {Cat }}\right.$ $=500{ }^{\circ} \mathrm{C}, \mathrm{T}_{\text {mem }}=370^{\circ} \mathrm{C} ; \mathrm{Q}_{\text {sweep }}=1.5 \mathrm{NL} / \mathrm{min} ; \mathrm{p}=5 \mathrm{barg}$ ).

The Figure 12 confirmed that for the selected operating conditions the thermodynamic equilibrium is well approached: such achievement demonstrates that the overall system is not limited by the catalytic stages. In particular, it was evidenced that the second and third catalytic reactors better approached the equilibrium, thus no inhibiting effects were devoted to the presence of propylene, while the hydrogen could operate a competitive adsorption on the catalytic surface, thus resulting in a limitation of the reaction kinetics [43]. Of course, such statements should be validated by dedicated tests, planned in the near future. Therefore, the different performances recorded with the two dilution ratios could be ascribable to a non-optimal separation efficiency of the membrane units. The Figure 13 evidenced that the hydrogen permeated through the membrane units is up to $60 \%$ lower than the ideal value (corresponding to the total permeation of hydrogen from the retentate side to the permeate side). In particular, the M-102 showed a lower

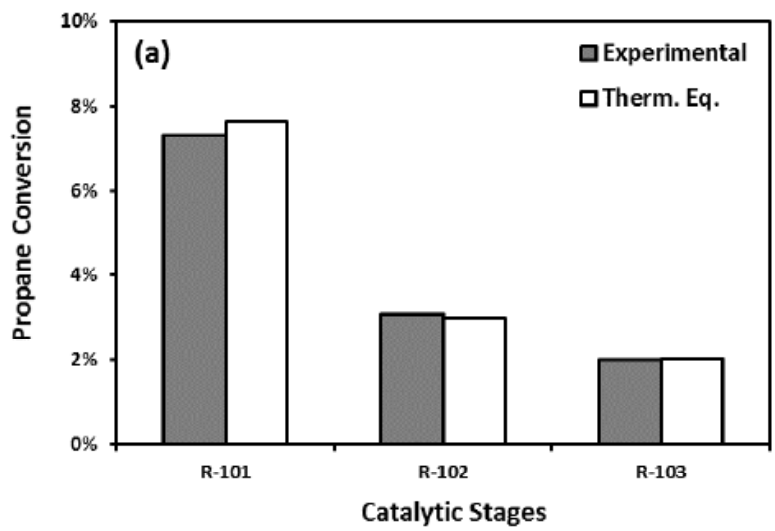

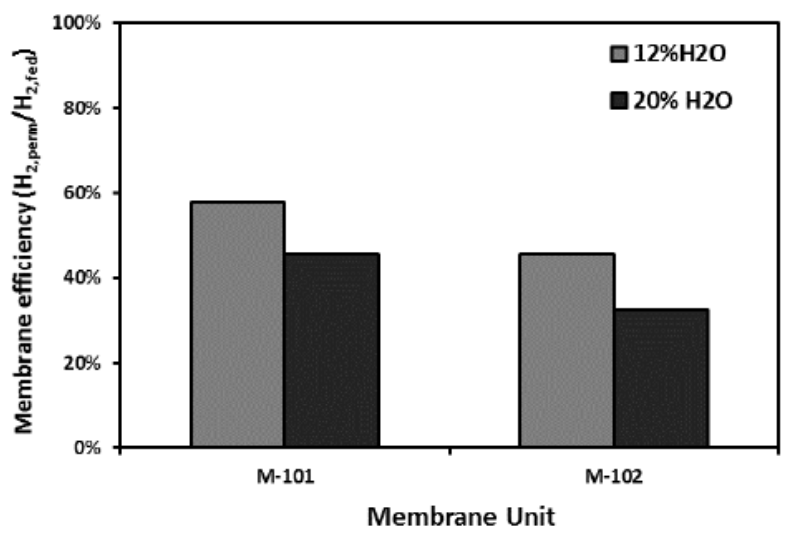

Figure 13: Hydrogen recovery conversion in the catalytic units during tests on membrane assisted system fed by $\mathrm{C}_{3} \mathrm{H}_{8}: \mathrm{H}_{2} \mathrm{O}=88: 12$ (a) and $\mathrm{C}_{3} \mathrm{H}_{8}: \mathrm{H}_{2} \mathrm{O}=80: 20$ (b) $\left(\mathrm{W}_{\mathrm{C} 3 \mathrm{H} 8}=\right.$ $0.25 \mathrm{~kg} / \mathrm{h}$; WHSV $=8 \mathrm{~h}^{-1}, \mathrm{~T}_{\text {Cat }}=500{ }^{\circ} \mathrm{C}, \mathrm{T}_{\text {mem }}=370{ }^{\circ} \mathrm{C}$; $\mathrm{Q}_{\text {sweep }}=1.5 \mathrm{NL} / \mathrm{min} ; \mathrm{p}=5 \mathrm{barg}$ ).

efficiency with respect to $M-101$, for both the selected operating conditions: of course, such achievement could be addressed to the lower hydrogen partial pressure in the retentate side of the second membrane unit with respect to the first one. In addition, steam dilution seems to play a negative effect on the membrane performances, since the separation efficiency appeared to be suppressed by higher steam dilution of the system. The overall performances of the membrane, therefore, are due to both a combination of aspects: in one hand the higher dilution of propane led to a higher dilution of products (steam was an inert in the process), therefore hydrogen partial pressure is reduced, depressing membrane performances. On the other hand, the higher content of steam led to a reduction in membrane permeance (of about $25 \%$ ), as also evidenced in Figure 9, since a competitive adsorption of $\mathrm{H}_{2} \mathrm{O}$ on $\mathrm{Pd}$ surface could take place.

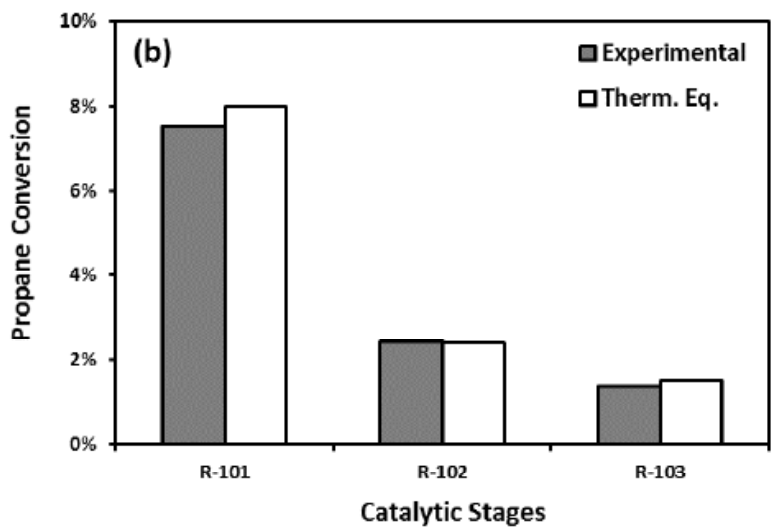

Figure 12: Propane conversion in the catalytic units during tests on membrane assisted system fed by $\mathrm{C}_{3} \mathrm{H}_{8}: \mathrm{H}_{2} \mathrm{O}=88: 12$ (a) and $\mathrm{C}_{3} \mathrm{H}_{8}: \mathrm{H}_{2} \mathrm{O}=80: 20$ (b) $\left(\mathrm{W}_{\mathrm{C} 3 \mathrm{H} 8}=0.25 \mathrm{~kg} / \mathrm{h} ; \mathrm{WHSV}=8 \mathrm{~h}^{-1}\right.$, $\left.\mathrm{T}_{\text {Cat }}=500^{\circ} \mathrm{C}, \mathrm{T}_{\text {mem }}=370{ }^{\circ} \mathrm{C} ; \mathrm{Q}_{\mathrm{sweep}}=1.5 \mathrm{NL} / \mathrm{min} ; \mathrm{p}=5 \mathrm{barg}\right)$. 
The combination of catalytic and separation units determined the overall performances of the system: in Figure 14 the propane conversion profile along the system was reported for the two dilution ratios. The reported results once again confirmed the better performances achieved for the lower dilution ratio: despite the more advantageous conditions (under the thermodynamic point of view) related to the higher dilution, the negative effect on the membranes of steam led to a reduced activity of the separation units, that in turn depressed the overall performances of the system. Globally, such achievement evidenced that in one hand the integrated approach assured a clear increasing in system performances; anyway the system configuration was limited by the separation units, that requires actions to improve efficiency.

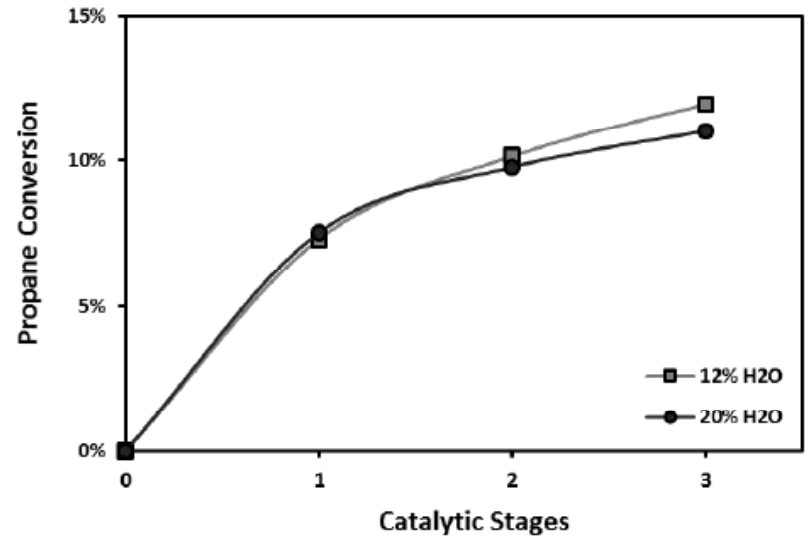

Figure 14: Dependence of propane conversion trend on feed dilution in the membrane assisted system $\left(\mathrm{W}_{\mathrm{C} 3 \mathrm{H} 8}=0.25 \mathrm{~kg} / \mathrm{h}\right.$; $\mathrm{WHSV}=8 \mathrm{~h}^{-1}, \mathrm{~T}_{\text {Cat }}=500{ }^{\circ} \mathrm{C}, \mathrm{T}_{\text {mem }}=370{ }^{\circ} \mathrm{C} ; \mathrm{Q}_{\text {sweep }}=1.5$ $\mathrm{NL} / \mathrm{min} ; \mathrm{p}=5$ barg)

\section{CONCLUSIONS}

The applicability of a membrane-assisted process in the propylene production via propane dehydrogenation has been investigated. The approach was based on the insertion of $\mathrm{Pd}$ based membranes between two catalytic stages for the recovery of hydrogen, thus promoting the chemical equilibrium of the PDH reaction aimed to the attainment of a sustainable propane conversion at lower temperature, so minimizing the contribution of side products. In the study, the criticism of the correct choice of the operating conditions was emerged, both for the catalytic reaction unit and for the separation module.

In one hand, catalytic tests on the reaction unit evidenced that the operating temperature strongly affects the propane conversion, since high temperature thermodynamically promotes high conversion degrees; on the other hand, too high temperature leads to not negligible values of formation of side-products, thus suppressing the selectivity to propylene. In addition, the presence of steam is crucial for the reaction, since its presence partially reduced the side-reaction towards the formation of coke or gaseous side-products. It is however worth to consider that the process stream dilution could counter the benefits linked to a membrane-assisted process, since it decreases the hydrogen partial pressure in the retentate side, thus the permeation flux. In addition, it was evidenced that the investigated catalytic system was able to totally inhibit steam reforming reactions, in the whole range of the investigated conditions.

The membrane characterization evidenced a weak dependence of the permeability from the operating temperature, since hydrogen flux could increase up to $30 \%$ by raising temperature of around $80^{\circ} \mathrm{C}$. On the other hand, experimental test evidenced that the presence of steam could partially suppress the permeability of the membrane.

Tests on the integrated system merged the effects on both catalytic reaction units and separation units. The results of the overall membrane based system show that the coupling of PDH reaction units with membrane can lead to an overcome of the thermodynamic equilibrium, thereby assessing the feasibility of this option. It was demonstrated that by using the proposed architecture, the propylene productivity was increased of about $50 \%$ with respect to the thermodynamic prediction for a traditional catalytic stage. Beside the promising results observed in the experimental tests for the membrane assisted systems, optimization in catalytic mass, membrane surface and processed flow stream appeared necessary [44]. However, the potential of membrane deactivation likely owing to adsorption of hydrocarbon species on the membrane surface can reduce the industrial applicability of this scheme. Accordingly, improvement in membrane formulation and long term tests are still needed to perform a complete assessment of the novel technology.

\section{ACKNOWLEDGEMENT}

The research leading to these results has received funding from the European Union Seventh Framework Programme FP7-NMP-2010-Large-4, under Grant Agreement no. 263007 (acronym CARENA). 


\section{NOMENCLATURE}

$\Delta H_{298 K}^{\circ}$ Reaction enthalpy at standard conditions, $\mathrm{kJ} \mathrm{mol}^{-1}$

$\delta \quad$ membrane layer thickness, $\mathrm{m}$

$F_{A} \quad$ Molar flow rate of $A$ species

GHSV Gas Hourly Space Velocity, $\mathrm{h}^{-1}$

$j_{H 2} \quad$ Hydrogen flux through the membrane layer, mol $\mathrm{m}^{-2}$ $\mathrm{s}^{-1}$

$p \quad$ Pressure, barg

$p_{H 2, \text { perm }}$ Hydrogen partial pressure in the permeate side, $\mathrm{Pa}$

$p_{H 2, \text { ret }}$ Hydrogen partial pressure in the retentate side, $\mathrm{Pa}$

$\mathrm{Pe} \quad$ Membrane permeability, mol m $\mathrm{m}^{-2} \mathrm{~s}^{-1} \mathrm{~Pa}^{-\mathrm{n}}$

Q Volumetric flow rate, NL $\mathrm{min}^{-1}$

R2 Determination factor, -

$S_{A} \quad$ Selectivity toward the A species, -

$T \quad$ Temperature, ${ }^{\circ} \mathrm{C}$

$X_{\text {C3H8 }} \quad$ Propane conversion, \%

WHSV Weight Hourly Space Velocity, $\mathrm{h}^{-1}$

\section{Acronyms}

PDH Propane DeHydrogenation

CTP Coal To Propylene

SC Steam Cracking

FCC Fluid Catalytic Cracking

STAR STeam Active Reforming

FBD Fluidized Bed Dehydrogenation

$\mathrm{DH} \quad$ DeHydrogenation

FID Flame lonization Detector

TCD Thermal Conductivity Detector

\section{REFERENCES}

[1] Propane dehydrogenation: producers are addressing the propylene deficit, Focus Catal 2017; 5 . https://doi.org/10.1016/j.focat.2017.10.028

[2] Corma A, Mengual J, Miguel PJ. IM-5 zeolite for steam catalytic cracking of naphtha to produce propene and ethene. An alternative to ZSM-5 zeolite, Appl Catal A Gen 2013; 460461 106-115.

https://doi.org/10.1016/j.apcata.2013.02.030

[3] Gao X, Tang Z, Zhang H, Ji D, Lu G, Wang Z, Tan Z. Influence of particle size of ZSM-5 on the yield of propylene in fluid catalytic cracking reaction, J Mol Catal A Chem 2010; 325: 36-39.

https://doi.org/10.1016/j.molcata.2010.03.026
Ibarra Á, Veloso A, Bilbao J, Arandes JM, Casta-o P. Dual coke deactivation pathways during the catalytic cracking of raw bio-oil and vacuum gasoil in FCC conditions, Appl Catal B Environ 2016; 182: 336-346.

https://doi.org/10.1016/j.apcatb.2015.09.044

[5] Heinritz-Adrian M, Wenzel S, Youssef F. Advanced propane dehydrogenation, Pet Technol Q 2008; 13: 83-91. https://www.scopus.com/inward/record.uri?eid=2-s2.0-

38849153016\&partner|D=40\&md5=01b04b4bd70ac1ea92e 8 3e606aa0d290.

[6] Bekmukhamedov G, Mukhamed'yarova A, Egorova S Lamberov A. Modification by $\mathrm{SiO} 2$ of Alumina Support for Light Alkane Dehydrogenation Catalysts, Catalysts 2016; 6: 162. http://www.mdpi.com/2073-4344/6/10/162. https://doi.org/10.3390/catal6100162

[7] Sui ZJ, Zhu YA, Li P, Zhou XG, Chen D. Kinetics of catalytic dehydrogenation of propane over Pt-based catalysts, 1st ed., Elsevier Inc. 2014.

https://doi.org/10.1016/B978-0-12-419974-3.00002-6

[8] Burch R, Garla LC, Platinum-tin reforming catalysts, J Catal 1981; 71: 360-372. https://doi.org/10.1016/0021-9517(81)90239-6

[9] Wang G, Zhang H, Zhu Q, Zhu X, Li X, Wang H, Li C, Shan $\mathrm{H}$. Sn-containing hexagonal mesoporous silica (HMS) for catalytic dehydrogenation of propane: An efficient strategy to enhance stability, J Catal 2017; 351: 90-94. https://doi.org/10.1016/j.jcat.2017.04.018

[10] Vu BK, Song MB, Ahn IY, Suh YW, Suh DJ, Kim WI, Koh HL, Choi YG, Shin EW. Pt-Sn alloy phases and coke mobility over Pt-Sn/Al2O3 and Pt-Sn/ZnAl2O4 catalysts for propane dehydrogenation, Appl Catal A Gen 2011; 400: 25-33. https://doi.org/10.1016/j.apcata.2011.03.057

[11] Verbeek $\mathrm{H}$, Sachtler WMH. The study of the alloys of platinum and tin by chemisorption, J Catal 1976; 42: 257267.

https://doi.org/10.1016/0021-9517(76)90260-8

[12] Wang $G$, Zhang $H$, Wang $H$, Zhu Q, Li C, Shan $H$. The role of metallic $\mathrm{Sn}$ species in catalytic dehydrogenation of propane: Active component rather than only promoter, J Catal 2016; 344: 606-608. https://doi.org/10.1016/j.jcat.2016.11.003

[13] Sun C, Luo J, Cao M, Zheng P, Li G, Bu J, Cao Z, Chen S, Xie X. A comparative study on different regeneration processes of $\mathrm{Pt}-\mathrm{Sn} / \mathrm{Y}-\mathrm{Al} 2 \mathrm{O} 3$ catalysts for propane dehydrogenation, J Energy Chem 2018; 27: 311-318.

https://doi.org/10.1016/j.jechem.2017.09.035

[14] Liu X, Lang WZ, Long LL, Hu CL, Chu LF, Guo YJ. Improved catalytic performance in propane dehydrogenation of $\mathrm{PtSn} / \mathrm{Y}$ Al2O3 catalysts by doping indium, Chem Eng J 2014; 247: 183-192. https://doi.org/10.1016/j.cej.2014.02.084

Wei C, Xue F, Miao C, Yue Y, Yang W, Hua W, Gao Z. Dehydrogenation of Isobutane with Carbon Dioxide over SBA-15-Supported Vanadium Oxide Catalysts, Catalysts 2016; 6: 171. http://www.mdpi.com/2073-4344/6/11/171. https://doi.org/10.3390/catal6110171

[16] Li Q, Sui Z, Zhou X, Zhu Y, Zhou J, Chen D. Coke Formation on Pt-Sn/Al2O3 Catalyst in Propane Dehydrogenation: Coke Characterization and Kinetic Study, Top Catal 2011; 54: 888. https://doi.org/10.1007/s11244-011-9708-8

[17] Han J, Jiang G, Han S, Liu J, Zhang Y, Liu Y et al. The Fabrication of Ga2O3/ZSM-5 Hollow Fibers for Efficient Catalytic Conversion of n-Butane into Light Olefins and Aromatics, Catalysts 2016; 6: 13. http://www.mdpi.com/20734344/6/1/13.

https://doi.org/10.3390/catal6010013

[18] Shan Y, Sui Z, Zhu Y, Chen D, Zhou X. Effect of steam addition on the structure and activity of Pt-Sn catalysts in propane dehydrogenation, Chem Eng J 2015; 278: 240-248. https://doi.org/10.1016/j.cej.2014.09.107 
[19] Zangeneh FT, Taeb A, Gholivand K, Sahebdelfar S. Kinetic study of propane dehydrogenation and catalyst deactivation over Pt-Sn/Al2O3 catalyst, J Energy Chem 2013; 22: 726732.

\section{https://doi.org/10.1016/S2095-4956(13)60096-0}

[20] Miraboutalebi SM, Vafajoo L, Kazemeini M, Fattahi M. Simulation of Propane Dehydrogenation to Propylene in a Radial-Flow Reactor over Pt-Sn/Al2O3as the Catalyst, Chem Eng Technol 2015; 38: 2198-2206. https://doi.org/10.1002/ceat.201500082

[21] Lobera MP, Téllez C, Herguido J, Menéndez M. Transient kinetic modelling of propane dehydrogenation over a Pt-SnK/AI2O3 catalyst, Appl Catal A Gen 2008; 349: 156-164. https://doi.org/10.1016/j.apcata.2008.07.025

[22] Czuprat O, Caro J, Kondratenko VA, Kondratenko EV. Dehydrogenation of propane with selective hydrogen combustion: A mechanistic study by transient analysis of products, Catal Commun 2010; 11: 1211-1214. https://doi.org/10.1016/j.catcom.2010.07.009

[23] Shelepova EV, Vedyagin AA, Mishakov IV, Noskov AS. Simulation of hydrogen and propylene coproduction in catalytic membrane reactor, Int J Hydrogen Energy 2015; 40: 3592-3598. https://doi.org/10.1016/i.ijhydene.2014.09.004

[24] Quicker P, Höllein V, Dittmeyer R. Catalytic dehydrogenation of hydrocarbons in palladium composite membrane reactors, Catal Today 2000; 56: 21-34.

https://doi.org/10.1016/S0920-5861(99)00259-X

[25] Moparthi A, Uppaluri R, Gill BS. Economic feasibility of silica and palladium composite membranes for industrial dehydrogenation reactions, Chem Eng Res Des 2010; 88: 1088-1101. https://doi.org/10.1016/i.cherd.2010.01.013

[26] Gbenedio E, Wu Z, Hatim I, Kingsbury BFK, Li K. A multifunctional $\mathrm{Pd} /$ alumina hollow fibre membrane reactor for propane dehydrogenation, Catal Today 2010; 156: 93-98. https://doi.org/10.1016/j.cattod.2010.04.044

[27] Ockwig NW, Nenoff TM. Membranes for Hydrogen Separation, Chem Rev 2007; 107: 4078-4110. https://doi.org/10.1021/cr0501792

[28] Montesinos H, Julián I, Herguido J, Menéndez M. Effect of the presence of light hydrocarbon mixtures on hydrogen permeance through $\mathrm{Pd}-\mathrm{Ag}$ alloyed membranes, Int $\mathrm{J}$ Hydrogen Energy 2015; 40: 3462-3471. https://doi.org/10.1016/j.ijhydene.2014.11.054

[29] Medrano JA, Julián I, Herguido J, Menéndez M. Pd-Ag Membrane Coupled to a Two-Zone Fluidized Bed Reactor (TZFBR) for Propane Dehydrogenation on a Pt-Sn/MgAl2O4 Catalyst, Membranes (Basel) 2013; 3: 69. http://www.mdpi.com/2077-0375/3/2/69. https://doi.org/10.3390/membranes3020069

[30] Peters TA, Polfus JM, van Berkel FPF, Bredesen R. Interplay between propylene and $\mathrm{H} 2 \mathrm{~S}$ co-adsorption on the $\mathrm{H} 2$ flux characteristics of $\mathrm{Pd}$-alloy membranes employed in propane dehydrogenation (PDH) processes, Chem Eng J 2016; 304: 134-140.

https://doi.org/10.1016/j.cej.2016.06.065

[31] Gimeno MP, Wu ZT, Soler J, Herguido J, Li K, Menéndez M. Combination of a Two-Zone Fluidized Bed Reactor with a Pd hollow fibre membrane for catalytic alkane dehydrogenation,
Chem Eng J 2009; 155: 298-303. https://doi.org/10.1016/j.cej.2009.06.037

[32] Peters TA, Liron O, Tschentscher R, Sheintuch M, Bredesen $\mathrm{R}$. Investigation of $\mathrm{Pd}$-based membranes in propane dehydrogenation (PDH) processes, Chem Eng J 2016; 305: 191-200. https://doi.org/10.1016/j.cej.2015.09.068

[33] Schäfer R, Noack M, Kölsch P, Stöhr M, Caro J. Comparison of different catalysts in the membrane-supported dehydrogenation of propane, Catal Today 2003; 82: 15-23. https://doi.org/10.1016/S0920-5861(03)00198-6

[34] Palo E, laquaniello G. Method for olefins production, 2012. https://www.google.ch/patents/WO2012134284A1?cl=en.

[35] Croppi C, Martorelli FS, Palo E, laquaniello G, Salladini A. System and method for the production of alkenes by the dehydrogenation of alkanes, 2016. https://www.google.com/patents/WO2016140574A1?cl=ar.

[36] Sheintuch M, Nekhamkina O. Architecture alternatives for propane dehydrogenation in a membrane reactor, Chem Eng J 2018; 347: 900-912. https://doi.org/10.1016/j.cej.2018.04.137

[37] Ricca A, Palma V, laquaniello G, Palo E, Salladini A. Highly selective propylene production in a membrane assisted catalytic propane dehydrogenation, Chem Eng J 2017; 330: 1119-1127. https://doi.org/10.1016/j.cej.2017.08.064

[38] Abir $\mathrm{H}$, Sheintuch M. Modeling $\mathrm{H} 2$ transport through a $\mathrm{Pd}$ or $\mathrm{Pd} / \mathrm{Ag}$ membrane, and its inhibition by co-adsorbates, from first principles, J Memb Sci 2014; 466: 58-69. https://doi.org/10.1016/j.memsci.2014.04.028

[39] Collins JP, Schwartz RW, Sehgal R, Ward TL, Brinker CJ, Hagen GP, Udovich CA. Catalytic Dehydrogenation of Propane in Hydrogen Permselective Membrane Reactors, Ind Eng Chem Res 1996; 35: 4398-4405. https://doi.org/10.1021/ie960133m

[40] Jung SH, Kusakabe K, Morooka S, Kim SD. Effects of coexisting hydrocarbons on hydrogen permeation through a palladium membrane, J Memb Sci 2000; 170: 53-60. https://doi.org/10.1016/S0376-7388(99)00357-9

[41] Patrascu M, Sheintuch M. On-site pure hydrogen production by methane steam reforming in high flux membrane reactor: Experimental validation, model predictions and membrane inhibition, Chem Eng J 2015; 262: 862-874. https://doi.org/10.1016/j.cej.2014.10.042

[42] Karagiannakis G, Zisekas S, Kokkofitis C, Stoukides M. Effect of $\mathrm{H} 2 \mathrm{O}$ presence on the propane decomposition reaction over $\mathrm{Pd}$ in a proton conducting membrane reactor, Appl Catal A Gen 2006; 301: 265-271. https://doi.org/10.1016/j.apcata.2005.12.017

[43] Ricca A, Montella F, laquaniello G, Palo E, Salladini A, Palma V. Membrane assisted propane dehydrogenation: Experimental investigation and mathematical modelling of catalytic reactions, Catal Today 2017.

https://doi.org/10.1016/j.cattod.2017.10.017

[44] Shelepova EV, Vedyagin AA, Mishakov IV, Noskov AS. Mathematical modeling of the propane dehydrogenation process in the catalytic membrane reactor, Chem Eng J 2011; 176-177: 151-157. https://doi.org/10.1016/j.cej.2011.06.048 